Maeda N. et al.

Running title: KIR expression in endometriosis 


\title{
Increased killer inhibitory receptor 2DL1 expression among natural killer cells in women with pelvic endometriosis
}

\author{
Nagamasa Maeda, M.D. Chiaki Izumiya, Yorito Yamamoto, \\ and Takao Fukaya, M.D.
}

Department of Obstetrics and Gynecology, Kochi Medical School, Kohasu, Oko, Nankoku, Kochi, Japan

All correspondence concerning this paper should be address to:

Nagamasa Maeda, M.D.

Department of Obstetrics and Gynecology

Kochi Medical School, Oko, Nankoku, Kochi, Japan 783-8505. 
Maeda N. et al.

\section{Capsule}

Compared with control, women with endometriosis showed more inhibitory receptor expression by natural killer cells in peritoneal fluid and peripheral blood. This may favor immunotorelance of endometriotic implants. 


\begin{abstract}
Objective: To investigate the host immunologic response to endometriosis in terms of killer inhibitory receptor (KIR) expression by natural killer (NK) cells.

Design: Case-control study of immunologic markers.

Setting: University hospital.

Patient(s): We compared cells from Japanese women laparoscopically diagnosed with endometriosis to cells from 40 women with other laparoscopic diagnoses.

Intervention(s): Peripheral venous blood sampling and laparoscopic peritoneal fluid collection.
\end{abstract}

Main Outcome Measure(s): KIR expression by NK cells was assessed in the above samples by flow cytometry.

Result(s): In women with endometriosis, the percentage of KIR2DL1-expressing NK cells among NK cells in both peritoneal fluid and peripheral blood was significantly higher than in control subjects. No significant differences in proportion of KIR2DL1 ${ }^{+} \mathrm{NK}$ cells were identified between peripheral blood NK cells sampled before and 1 month after laparoscopic surgery.

Conclusion (s): KIR2DL1 ${ }^{+}$NK cells were increased in peripheral blood from women with endometriosis, a difference likely to be related to immunesuppression in endometriosis. This increase in KIR2DL1 expression among NK cells may represent a pathogenetic factor in endometriosis.

Key words: killer inhibitory receptor, natural killer cells, immunesuppression 


\section{Introduction}

The pathogenesis of endometriosis is incompletely understood. In the past decade, host immune responses have received increasing attention with respect to in initiation and progression of this condition (1-4). Cells in the peritoneal fluid include some methotherial cells but are mainly mononuclear cells. Among these mononuclear cells, $90 \%$ are macrophages. Other mononuclear cells in this fluid include lymphocytes and natural killer (NK) cells. Macrophages, lymphocytes, and NK cells all are immunocompetent, and impairment of their responses against endometrial epithelial and stromal cells is considered pathologically important in endometriosis (1-4).

NK cells have cytotoxic effect against target cells even in the absence of antigen sensitization (5). NK cells participate in host defenses against infections (6) and antitumor effects (7), unfavorable NK effects may occur with respect to pregnancy (spontaneous abortion) (8), and tissue transplantation (rejection) (9). Since decreased NK cell activity in peripheral blood (10) and in peritoneal fluid $(11,12)$ first were reported in women with endometriosis, many additional investigators have described functional depression of NK cells in this disorder (13, 14). Decreased NK activity in women with endometriosis is considered to promote implantation of the endometrium as a tissues graft (9), but the mechanisms that suppress NK cell activity in endometriosis are not clear. Killer inhibitory receptors (KIR) recently have been identified on NK cells (15). KIR inhibits NK cell cytotoxicity against target cells after recognition of "self” determinations for major histocompatibility antigen complex (MHC) class 
I (15). Thus, NK cell toxicity against target cell is considered to be regulated by KIR expression. Wu et al. (16) reported increased KIR expression on peritoneal NK cells from women with endometriosis, which represents likely causes of decreased peritoneal NK activity in these patients.

In the present investigation, the percentage of KIR2DL1; a member of KIR family, -expressing (KIR2DL1 ${ }^{+}$) NK cells among NK cells in peritoneal fluid and peripheral blood were increased in women with endometriosis compared to controls. Relationships between percentage of KIR2DL1 ${ }^{+} \mathrm{NK}$ cells and clinical severity were examined. The percentage of KIR2DL1 ${ }^{+} \mathrm{NK}$ cells in peripheral blood also was reexamined after laparoscopic removal of endometriotic lesions.

\section{Materials and methods}

\section{Subjects}

Forty-two women with endometriosis [6 with stage I disease according to the revised classification of the American Society for Reproductive Medicine (r-ASRM); 6, stage II; 10, stage III; and 20, stage IV] (17) were examined laparoscopically, as were 40 women with other conditions (control group; 15 with uterine myoma, 14 with benign ovarian cysts, 7 with infertility, 2 with paraovarian cysts, and 2 with carcinoma in situ of the uterine cervix). Laparoscopic examinations and surgery were performed in the Department of Obstetrics and 
Gynecology of Kochi Medical School between April 1999 and January 2001. In women with endometriosis, the various laparpscopic operations performed included electro cautery, lysis of adhesions, and removal of endometriotic cysts. Mean ages for the group with endometriosis and the control groups were $32.0 \pm 7.2$ and $35.0 \pm 9.2$, respectively (no significant difference). Women with a history of pregnancy less than 3 years previously or a history of treatment with gonadotropin-releasing hormone agonists within a similar period, as well as those suspected to have complications of pelvic inflammatory disease, were excluded from analysis. Informed consent for obtaining peritoneal fluid samples during laparoscopy was obtained before the procedure, as it was for peripheral blood sampling. This study was approved by the institutional review board of Kochi Medical School Hospital.

\section{Blood and peritoneal fluid samples}

Peripheral blood (2 ml) was collected in heparinized Hank's buffer before laparoscopy, and in 12 subjects with endometriosis, also 1 month after laparoscopic surgery (see Results). Peritoneal fluid identified within the abdominal cavity was collected in heparinized Hank's buffer at laparoscopy.

\section{Monoclonal antibodies}

Fluorescein isothiocyanate (FITC)-labeled anti-CD16 monoclonal antibody (mAb) was used to identify NK cells (Beckman-Coulter, California, USA). Phycoerythrin (PE)-labeled anti-CD158a, anti-CD158b, and CD94 mAbs were used as markers for killer-cell inhibitory receptor (KIR) on NK cells (Beckman-Coulter). Anti-CD158a and anti-CD158b mAbs were used to identify KIR2DL1 and KIR2DL2 expressed on NK cells, respectively. Peripheral blood 
mononuclear cells (PBMC) or peritoneal fluid mononuclear cells (PFMC) were allowed to react with the mAbs and then were evaluated by flow cytometry, as described below.

\section{Flow cytometry}

The mAbs (each $5 \mu$ l) was added together to a 200- $\mu$ l aliquot of peripheral blood sample and allowed to react at room temperature for $1 \mathrm{~h}$. Peritoneal fluid cells were resuspended in phosphate-buffered saline (PBS) after pelleting by centrifugation at $1500 \mathrm{rpm}$ for $7 \mathrm{~min}$; then mAbs were added as for peripheral blood and allowed to react at room temperature for $1 \mathrm{~h}$.

After the mAb reaction, erythrocytes were hemolyzed in ammonium chloride; then each cell sample was centrifuged and resuspended in $0.5 \mathrm{ml}$ of PBS. An EPICS ELITE flow cytometer (Beckman-Coulter) was used for analysis of fluorescence from the two contrasting mAbs. The area corresponding to lymphocytes in plots of mononuclear cell fractions in each sample was gated with forward-scattered and laterally scattered light, and fluorescence intensities of cell populations in this region were measured.

\section{KIR}

KIR2DL1, KIR2DL2, and CD94 expression on NK cells were measured. The abundance of each $\mathrm{KIR}^{+} \mathrm{NK}$ cells is expressed as a percentage of all NK cells in the sample. In some women with endometriosis, the percentage of KIR2DL1 ${ }^{+} \mathrm{NK}$ cells among all NK cells in PBMC was redetermined 1 month after laparoscopic surgery.

\section{Results}


In our previous study, relative numbers of NK cells in PBMC or PFMC did not differ significantly between women with and without endometriosis. In the present investigation, when we examined expression of KIR among NK cells in PFMC in women with endometriosis, the percentage of KIR2DL1 ${ }^{+} \mathrm{NK}$ cells was $20.3 \pm 14.9$, significantly higher than in women without endometriosis $(12.0 \pm 6.9, \mathrm{p}=.017$ by student-t test; Table 1$)$. When relationships between percentage of KIR2DL1 ${ }^{+} \mathrm{NK}$ cells and clinical stage were examined, the percentage of KIR2DL1 ${ }^{+} \mathrm{NK}$ in PFMC in advanced disease (stages III and IV); (24.2 \pm 16.1 ) was significantly higher than in women without endometriosis ( $\mathrm{p}=.017$ by Mann-Whitney’s U and Kruskal-Wallis tests; Table 1). No significant differences were identified between samples representing early disease (stages I and II); (11.9 \pm 9.3$)$ and samples from women without endometriosis ( $p=.70$ by Mann-Whitney’s U and Kruskal-Wallis tests; Table 1). The percentage of KIR2DL1 ${ }^{+} \mathrm{NK}$ cells in PFMC in advanced disease also was significantly higher than in early disease ( $p=0.049$ by Mann-Whitney’s U test). In PBMC from women with endometriosis, the percentage of KIR2DL1 ${ }^{+} \mathrm{NK}$ cells was $17.4 \pm 8.4$, significantly higher than in women without endometriosis $(11.7 \pm 5.5, \mathrm{p}=.0008$ by student-t test; Table 1$)$. The percentage of KIR2DL1 ${ }^{+} \mathrm{NK}$ cells in PBMC in advanced disease; $16.8 \pm 8.5$ was significantly higher than in women without endometriosis ( $\mathrm{p}=.009$ by Mann-Whitney’s $U$ and Kruskal-Wallis tests; Table 1), as also was true in early disease; (17.8 \pm 8.3 , p=.008 by Mann-Whitney’s U and Kruskal-Wallis tests; Table 1). No significant differences were identified between early disease and advanced disease.

There was no statistically significant difference in the percentage of KIR2DL2 ${ }^{+} \mathrm{NK}$ cells and 
$\mathrm{CD}^{+}{ }^{+} \mathrm{NK}$ cells from PBMC and PFMC among women with and without endometriosis (data not shown).

Percentages of KIR2DL1 ${ }^{+} \mathrm{NK}$ among NK cells in peritoneal fluid correlated with r-ASRM scores ( $p=.009$; Figure 1). However, percentages of KIR2DL1 ${ }^{+} \mathrm{NK}$ cells in peripheral blood did not show a correlation with r-ASRM sores $(\mathrm{p}=.78$; Figure 1$)$.

Percentages of KIR2DL1 ${ }^{+} \mathrm{NK}$ cells in peripheral blood of 12 subjects with endometriosis (2 in stage III and 10 in stage IV) were examined prior to and 1 month after performance of laparoscopic operations that variously included electro-cautery, lysis of adhesions, and removal of endometriotic cysts). The percentage of KIR2DL1 ${ }^{+} \mathrm{NK}$ among NK cells in PBMC was not significantly changed by treatment, and pretreatment and posttreatment values were higher than those in control subjects (Table 2).

\section{Discussion}

The pathogenesis of endometriosis remains largely unexplained. Since ectopic endometrium can proliferate in response to hormonal influences and ultimately can show tumorlike behavior, analogies to antitumor immunity might be considered (1-4). Accordingly, in the past decade, host immune responses have received increasing attention with respect to the pathogenesis and progression of endometriosis $(18,19)$. Increased numbers of macrophage $(20)$, and increased macrophage-derived cytokines (21-24) have been found in peritoneal fluid from women with 
Maeda N. et al.

endometriosis. Simultaneous decreases in activation of macrophages with respect to decreased phagocytosis $(25)$ and cytotoxity $(26,27)$ are also reported. Furthermore, decreased immune responses, such as functional depression of $\mathrm{T}$ cells (28) and the presence of soluble inter cellular adhesion molecule (ICAM)-1 (29) in peritoneal fluid; ICAM-1 modulates signal transduction between immunocompetent cells. Since the initial report of decreased NK cell activity in peripheral blood (10) and peritoneal fluid (11, 12), many investigators demonstrated functional depression of NK cells in women with endometriosis $(13,14)$. NK cells attack target cells without requiring antigen sensitization (5). These cells participate in host defenses against infection (6) and antitumors (7), but can adversely affect pregnancy (8) and tissue grafting rejection (9). In endometriosis, decreased NK activity is considered to promote extrauterine implantation of endometrial tissue, but the causes of depressed NK cell activity are not clear. Karre et al. (30) proposed a "missing self” hypothesis in which NK cells are toxic to target cells that do not express MHC determinants characteristic of self, while toxicity against target cells that express these determinants is inhibited. This hypothesis is supported by the identification of KIRs on NK cells that recognize self-determinants in MHC class I (15), inhibiting NK cytotoxicity against target cells bearing the determinants. As expression of KIR appears to be related to NK cell activity (31), increased KIR expression on peritoneal NK cells in women with endometriosis (16) could partly explain decreased peritoneal NK cell activity. In our previous investigation, relative numbers of NK cells in peripheral blood and peritoneal fluid did not differ significantly between women with and without endometriosis. We therefore examined percentage of $\mathrm{KIR}^{+} \mathrm{NK}$ among NK cells. 
KIR expressed on the natural killer (NK) cells were composed of immunoglobrin superfamilies and lectin families. Immunoglobrin superfamily contrains KIR2DL1 and KIR2DL2. After recognizing the different HLA-C locus of the target cells, both KIRs inhibit the cytotoxicity of NK cells ( ). On the other, CD94/NKG2 complex is a lectin type KIR that is expressed on NK cells. The ligand of CD94/NKG2 is HLA-E on the target cells ( ). Then we measured the expression of KIR2DL1, KIR2DL2, and CD94 on NK cells in women with and without endometriosis.

The percentages of $\mathrm{KIR}^{2} \mathrm{DL} 2^{+} \mathrm{NK}$ and $\mathrm{CD}^{+} 4^{+} \mathrm{NK}$ cells among both peripheral blood monocytes and peritoneal macrophages were not significantly different between women with and without endometriosis.

In women with advanced endometriosis, the percentage of KIR2DL1 ${ }^{+} \mathrm{NK}$ among peritoneal NK cells was significantly higher than in women without endometriosis or with early disease, suggesting a progression-related decrease in NK activity in the peritoneal cavity. An increased percentage of KIR2DL $1^{+} \mathrm{NK}$ cells in peritoneal fluid might be caused by local cytokines interactions that influence cell proliferation and migration (32). The increased percentage of KIR2DL1 ${ }^{+} \mathrm{NK}$ cells is related to decreased NK activity in peritoneal fluid, and indicates a decrease in immune surveillance that otherwise would oppose implantation of endometrial cells and progression of endometriosis.

The percentage of KIR2DL1 ${ }^{+} \mathrm{NK}$ cells in peripheral blood from women with endometriosis was significantly higher than in women without endometriosis, suggesting a systemic decrease in NK activity. In blood, women in both early and advanced stages showed a significant 
higher percentage of KIR2DL1 ${ }^{+} \mathrm{NK}$ cells than women without endometriosis. Furthermore, percentages of KIR2DL1 ${ }^{+} \mathrm{NK}$ among NK cells in blood did not correlate with r-ASRM Scores. These differences in pattern suggest that increased KIR2DL1 ${ }^{+} \mathrm{NK}$ cells in peripheral blood are not simply a reflection of changes in peritoneal fluid.

The percentage of KIR2DL1 ${ }^{+} \mathrm{NK}$ cells in PBMC after laparoscopic surgery for endometriosis was not significantly different than that before surgery, and remained significantly higher than expression in control subjects. In a previous report, NK cell activity in peritoneal blood similarly failed to recover after LASER cautery of the endometriotic lesion (33). Like the differences seen between PBMC and PFMC, these preoperative/postoperative comparisons indicate the relative increase in KIR2DL1 $1^{+} \mathrm{NK}$ cells in PBMC of women with endometriosis was a primary event with pathogenetic importance. Increased KIR2DL1 ${ }^{+} \mathrm{NK}$ cells in peritoneal fluid might have resulted from migration of $\mathrm{KIR}^{+} \mathrm{NK}$ cells from peripheral blood. Increased KIR2DL1 $1^{+} \mathrm{NK}$ cells in the peripheral blood, then, ultimately suppress immunesurveillance in the peritoneal cavity against implanted endometrial cells.

Hornung et al. Reported that HLA-E, a ligand for CD94/NKG2 complex, is not expressed on endometriosis cells. This indicates that activated CD94/NKG2 on NK cells can not bind to endometriosis cells and suggests that CD94 is not related to unresponsiveness of NK cells. We would like to consider that KIR2DL1 is more related to unresponsiveness of NK cells in women with endometriosis rather than CD94. 
Maeda N. et al.

Epidemiologic observations demonstrating frequent familial occurrence of endometriosis (3436) indicate that genetic factors are involved in pathogenesis. Increased KIR ${ }^{+} \mathrm{NK}$ cells in blood

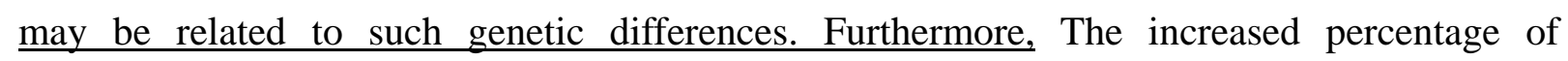
KIR2DL1-expressing NK cells suggests the existence of a high-risk group for endometriosis. Further analysis of $\mathrm{KIR}^{+} \mathrm{NK}$ cells in peripheral blood might contribute to elucidation the pathogenesis of endometriosis. 


\section{Reference}

1. Dmowski WP, Steele RW, Baker GF. Deficient cellular immunity in endometriosis. Am J Obstet Gynecol 1981;141:377-382

2. Semer D, Reisler K, MacDonald PC, Casey ML. Responsiveness of human endometrial stromal cells to cytokines. Ann NY Acad Sci 1991;622:99-102

3. Gilmore SM, Aksel S, Hoff C, Peterson RD. In vitro lymphocyte activity in women with endometriosis—an altered immuneresponce? Fertil Steril 1992;58:1148-1152

4. Ho HN, Wu MY, Yang YS. Peritoneal cellular immunity and endometriosis. Am J Reprod Immunol 1997;400-412

5. Klein E, Masucci MG, Masucci G, Vanky F. Natural killer activity of human blood lymphocytes. Mol Immunol. 1982 ;19:1323-1329

6. Holmberg LA, Ault KA. Characterization of natural killer cells induced in the peritoneal exudates of mice infected with Listeria monocytogenes: a study of their tumor target specificity and their expression of murine differentiation antigens and human NKassociated antigens. Cell Immunol. 1984; 89:151-168

7. Voogt PJ, Falkenburg JH, Fibbe WE, Veenhof WF, Hamilton M, Van Krimpen BA, Bolhuis RL. Normal hematopoietic progenitor cells and malignant lymphohematopoietic cells show different susceptibility to direct cell-mediated MHC-non-restricted lysis by T 
cell receptor-/CD3-, T cell receptor gamma delta ${ }^{+} / \mathrm{CD}^{+}{ }^{+}$and $\mathrm{T}$ cell receptor-alpha beta $^{+} / \mathrm{CD}^{+}$lymphocytes. J Immunol 1989; 142: 1774-1780

8. Kwak JY, Beaman KD, Gilman-Sachs A, Ruiz JE, Schewitz D, Beer AE. Up-regulated expression of $\mathrm{CD}_{56}{ }^{+}$, $\mathrm{CD}_{5} 6^{+} / \mathrm{CD} 16^{+}$, and CD19+ cells in peripheral blood lymphocytes in pregnant women with recurrent pregnancy losses. Am J Reprod Immunol. 1995;34:93-99

9. Lefkowitz M, Kornbluth J, Tomaszewski JE, Jorkasky DK. Natural killer-cell activity in cyclosporine-treated renal allograft recipients. J Clin Immunol 1988;8:121-127

10. Oosterlynck DJ, Cornillie FJ, Waer M, Vandeputte M, Koninckx PR. Women with endometriosis show a defect in natural killer activity resulting in a decreased cytotoxicity to autologous endometrium. Fertil Steril 1991;56:45-51

11. Oosterlynck DJ, Meuleman C, Waer M, Vandeputte M, Koninckx PR. The natural killer activity of peritoneal fluid lymphocytes is decreased in women with endometriosis. Fertil Steril 1992;58:290-295

12. Tanaka E, Sendo F, Kawagoe S, Hiroi M. Decreased natural killer cell activity in women with endometriosis. Gynecol Obstet Invest 1992;34:27-30

13. Wilson TJ, Hertzog PJ, Angus D, Munnery L, Wood EC, Kola I., Mori T.Decreased natural killer cell activity in endometriosis patients: relationship to disease pathogenesis. $1994 ; 62: 1086-1088$

14. Garzetti GG, Cignitti M, Ciavattini A, Fabris N, Romanini C. Decreased natural killer cell activity in women with endometriosis. Gynecol Obstet Invest 1992; 34: 27-30.

15. Moretta A, Sivori S, Vitale M, Pende D. Existence of both inhibitory(p58) and 
activatory(p50) receptors for HLA-C molecules in human naturak killer cells. J Exp Med 1995;182:875-884

16. Wu MY, Yang JH, Chao KH, Hwang JL, Yang YS, Ho HN. Increase in the expression of killer cell inhibitory receptors on peritoneal natural killer cells in women with endometriosis. Fertil Steril. 2000; 74:1187-1191

17. Schenken RS. Modern concepts of endometriosis. Classification and its consequences for therapy. J Reprod Med 1998 Mar;43:269-275.

18. Olive DL, Montoya I, Schenken RS. Macrophages-conditioned media enhance endometrial stromal cell proliferation in vitro. Am J Obstet Gynecol 1991;164:953958

19. Koninckx PR, Meuleman C, Demeyere S, Lesaffre E, Cornillie FJ. Suggestive evidence that pelvic endometriosis is a progressive disease, whereas deeply infiltrating endometriosis is associated with pelvic pain. Fertil Steril 1991;55:759-765

20. Hill JA, Faris HM, Schiff I, Anderson DJ. Characterization of leukocyte subpopulation in the peritoneal fluid of women with endometriosis. Fertil Steril $1988 ; 50: 216-222$

21. Ramey JW, Archer DF. Peritoneal fluid: its relevance to the development of endomtriosis. Fertil Steril 1993;60:1-14

22. Halme J, White C, Kauma S, Estes L, Haskill S. Peritoneal macrophages from patients with endometriosis release growth factor activity in vitro. J Clin Endocrinol Metab 
1988;66:1044-1049

23. Halme J. Release of tumor necrosis factor-alpha by human peritoneal macrophages in vivo and in vitro. Am J Obstet Gynecol 1989;161:1718-1722

24. Oosterlynck DJ, Meuleman C, Waer M, Koninckx PR, Vandeputte M. Immunosupressive activity of peritoneal fluid from women with endometriosis. Obstet Gynecol 1993;80:206-212

25. Steele RW, Dmowski WP, Marmer DJ. Immunologic aspects of human endometriosis. Am J Reprod Immunol 1984;6:33-36

26. Broun DP, Gebel H, Rotman C, Rana N, Dmowski WP. The development of cytotoxity in peritoneal macrophages from women with endometriosis. Fertil Steril 1992;57: 1203-1210

27. Oosterlynck DJ, Meuleman C, Waer M, Vandeputte M, Koninckx PR. The natural killer activity of peritoneal fluid lymphocytes is decreased in women with endometriosis. Fertil Steril 1992;58:290-295

28. Wu MY, Chao KH, Chen SU, Chen HF, Yang YS, Huang SC, Ho HN. The suppression of peritoneal cellular immunity in women with endometriosis could be restored after gonadotropin releasing hormone agonist treatment. Am J Reprod Immunol 1996 Jun;35:510-516

29. Fukaya T, Sugawara J, Yosida H, Yajima A. Intercellular adhesion molecule-1 amd hepatocyte growth factor in human endometriosis: original investigation and a review of literature. Gynecol Obstet Invest 1999;47:11-17

30. Karre K. Natural killer cells and the MHC class I pathway of peptide presentation. 
Maeda N. et al.

Semin Immunol 1993 ;5:127-145. Review.

31. Valiante NM, Phillips JH, Lanier LL, Parham P. Killer cell inhibitory receptor recognition of human leukocyte antigen (HLA) class I blocks formation of a pp36/PLC-gamma signaling complex in human natural killer (NK) cells. J Exp Med 1996;184:2243-50.

32. Poggi A, Costa P, Tomasello E, Moretta L. IL-12-induced up-regulation of NKRP1A expression in human NK cells and consequent NKRP1A-mediated down-regulation of NK cell activation. Eur J Immunol 1998;28:1611-1616.

33. Oosterlynck DJ, Cornillie FJ, Waer M, Vandeputte M, Koninckx PR. Women with endometriosis show a defect in natural killer activity resulting in a decreased cytotoxicity to autologous endometrium. Fertil Steril 1991;56:45-51

34. Malinak LR, Buttram VC, Elias S, Simpson JL. Heritable aspects of endometriosis. II. Clinical characteristics of familial endometriosis. Am J Obstet Gynecol 1980;137:332-337

35. Lamb K, Hoffmann RG, Nichols TR. Family trait analysis: A case-control study of 43 women with endometriosis and their best friends. Am J Obstet Gynecol 1986;154:596-601

36. Moen MH, Magnus P. The familial risk of endometriosis. Acta Obstet Gynecol Scand $1993 ; 72: 560-564$ 
Maeda N. et al.

\section{Legend}

\section{Figure. 1}

Correlation between disease progression (r-ASRM score) and percentage of KIR2DL1 ${ }^{+} \mathrm{NK}$ cells in peritoneal fluid $(\bigcirc)$ and peripheral blood $(\mathcal{O})$ in women with endometriosis. Percentages of KIR2DL1 ${ }^{+} \mathrm{NK}$ in peritoneal fluid $(\bigcirc)$, but not peripheral blood $(\mathbf{O})$, correlated with r-ASRM scores. Correlation was estimated by linear regression analysis. r-ASRM, revised classification of the American Society for Reproductive Medicine; KIR, killer inhibitory receptor; NK, natural killer. 